\title{
Diagnostic yield of computed tomography-guided bone biopsy and clinical outcomes of tuberculous and pyogenic spondylitis
}

\author{
Eun-Jeong Joo ${ }^{1}$, Joon-Sup Yeom ${ }^{1}$, Young Eun $\mathrm{Ha}^{2}$, So Yeon Park ${ }^{3}$, Chong-Suh Lee ${ }^{4}$, Eun-Sang Kim , \\ Cheol-In Kang ${ }^{2}$, Doo-Ryeon Chung ${ }^{2}$, Jae-Hoon Song ${ }^{2}$, and Kyong Ran Peck²
}

\begin{abstract}
${ }^{1}$ Division of Infectious Diseases, Department of Internal Medicine, Kangbuk Samsung Hospital, Sungkyunkwan University School of Medicine, Seoul; ${ }^{2}$ Division of Infectious Diseases, Department of Medicine, Samsung Medical Center, Sungkyunkwan University School of Medicine, Seoul; ${ }^{3}$ Division of Infectious Diseases, Department of Internal Medicine, Hallym University Kangdong Sacred Heart Hospital, Seoul; Departments of ${ }^{4}$ Orthopedic Surgery and ${ }^{5}$ Neurosurgery, Samsung Medical Center, Sungkyunkwan University School of Medicine, Seoul, Korea
\end{abstract}

Received: February 6, 2013 Revised : September 25, 2013 Accepted: December 13, 2013

\section{Correspondence to}

Kyong Ran Peck, M.D.

Division of Infectious Diseases, Department of Medicine, Samsung Medical Center, Sungkyunkwan University School of Medicine, 81 Irwon-ro, Gangnam-gu, Seoul 06351, Korea

Tel: $+82-2-3410-0322$

Fax: +82-2-3410-0064

E-mail:krpeck@skku.edu
Background/Aims: This study aimed to evaluate the efficacy of computed tomography (CT)-guided bone biopsy for the diagnosis of spinal infection and compared the clinical outcomes between tuberculous and pyogenic spinal infections. Methods: The retrospective cohort study included patients who received CT-guided bone biopsy at a tertiary hospital over the 13 years.

Results: Among 100 patients, 67 had pyogenic spondylitis and 33 had tuberculous spondylitis. Pathogens were isolated from bone specimens obtained by CT-guided biopsy in 42 cases, with diagnostic yields of $61 \%$ (20/33) for tuberculous spondylitis and $33 \%(22 / 67)$ for pyogenic spondylitis. For 36 culture-proven pyogenic cases, Staphylococcus aureus was the most commonly isolated organism. Patients with pyogenic spondylitis more frequently presented with fever accompanied by an increase in inflammatory markers than did those with tuberculosis. Among all patients who underwent surgery, the incidence of late surgery performed one month after diagnosis was higher in patients with tuberculous infection (56.3\%) than in those with pyogenic disease $(23.3 \%, p=0.026)$.

Conclusions: Results obtained by CT-guided bone biopsy contributed to prompt diagnoses of spinal infections, especially those caused by tuberculosis. Despite administration of anti-tuberculous agents, patients with tuberculous spondylitis showed an increased tendency to undergo late surgery.

Keywords: Spondylitis; Computed tomography; Biopsy; Tuberculosis; Percutaneous

\section{INTRODUCTION}

The incidence of spinal infection has grown rapidly with increasing uses of invasive spinal procedures and intravascular cathetes that can act as a means of inoc- ulation and spreading of pathogens into the vertebra, intervertebral disks, and adjacent muscles [1]. There is also an upward trend in spinal tuberculosis due to the growing number of immunocompromising conditions [2-5]. Even though the advanced diagnostic technology 
of magnetic resonance imaging (MRI) has improved the sensitivity and specificity of this disease entity, the diagnosis of spondylitis has been a challenge for physicians for many years [6].

Computed tomography (CT)-guided biopsy is a valuable tool in the diagnosis of musculoskeletal diseases. The value of this procedure in pyogenic spinal infection has been investigated in several studies, indicating a sensitivity range of $30 \%$ to $50 \%$ [7-9]. However, the diagnostic yield of CT-guided bone biopsy for spinal tuberculosis has rarely been exploited despite the recent rising prevalence of both tuberculous and pyogenic spinal infection $[10,11]$.

To evaluate the roles of CT-guided biopsy in tuberculous and pyogenic spondylitis, we conducted a retrospective cohort study in patients who were diagnosed with spine infection and who received a CT-guided bone biopsy over a 13-year period. Among recipients of CT-guided bone biopsies, we also compared the clinical outcomes between tuberculous and pyogenic spondylitis groups.

\section{METHODS}

\section{Study population and patient selection}

This retrospective cohort study was designed to identify the diagnostic yield of CT-guided bone biopsy and to evaluate the clinical outcomes in patients with spinal infection from March 1996 to March 2008 in a 1,900bed tertiary care university hospital. To search patients who have underwent CT-guided bone biopsy and diagnosed to have osteomyelitis, we screened cases in which "bone" specimen was obtained by "CT-guided procedure." Specimen code for "bone tissue" and procedure codes for "bone needle biopsy procedure" and "imaging guidance procedure" were used for screening cases. Electronic medical records were reviewed among screened individuals. From the medical records, we selected patients who had cultural and pathologic reports and radiologic findings compatible with those of pyogenic and tuberculous spondylitis. Based on histopathologic reports, cases proven to have malignancy or non-septic inflammatory discitis were excluded. Finally adults patients, who had underwent CT-guided bone biopsy and been diagnosed to have infectious spondylitis by the evidence of cultural, pathologic, and radiological data and been treated with prolonged antimicrobial therapy, were enrolled in the study.

\section{Definitions and data collection}

Patients with tuberculous spondylitis were categorized into definite, probable and possible groups, whereas those with pyogenic one were categorized into definite and possible. The definite group referred to cases with microbiologic evidence of bacteria, fungus or tuberculosis. The presence of caseating granulomatosis or acid-fast bacilli in Ziehl-Neelsen stained slides on histopathology defined probable tuberculosis in cases without mycobacterial growing. Detection of tuberculosis by polymerase chain reaction (PCR) was also used to aid the probable diagnosis when microbiologic evidence was not given [12]. The possible group contained cases that were clinically diagnosed and treated with conventional antibacterial and anti-tuberculous agents by attending physicians, based on clinical presentation and manifestation when test results from cultures, histopathology, and tuberculosis PCR failed to prove presumptive pathogen. Radiologic findings such as the patterns of destruction of vertebral end plates and signal-intensity changes of involved vertebrae, and presence of epidural, paravertebral, and dis-space abscess were also used to support a clinical diagnosis.

The following patient data were collected using electronic medical and laboratory records: initial clinical presentation such as fever, constitutional symptoms, and back pain; underlying comorbidity; laboratory data including white blood cell count (WBC), erythrocyte sedimentation rate (ESR), and C-reactive protein (CRP) level; involved vertebra; radiologic findings suggesting tuberculosis or pyogenic spinal infections, the presence of paravertebral or epidural abscess; results of histopathology; antibiotic regimen and duration of treatment; and performance of surgical intervention

Clinical improvement was assessed at 4 weeks during the course of therapy. Lack of improvement referred to the cases with persistent or aggravated back pain, necessity of abscess drainage, or development of neurologic deficit [13]. The patients were followed up for 6 months after completion of treatment. Clinical success was defined as cases without recurrence at 6 months after finishing treatment, whereas clinical failure was as those 
with death, relapse or repetitive surgery during the follow-up period.

The time of surgery was defined as days between the date of CT-guided bone biopsies and the date of surgical intervention. Types of surgical intervention were further classified into early and late surgery. The late cases were designated as those performed 1 month after diagnosis. The number and percentage of late surgeries was also calculated to evaluate the efficacy of initial medical treatment. The decision to perform early or late surgery was made by the attending surgeon. The reasons for late surgical approach were divided into two categories whether it was initially planned at the time of diagnosis when the early surgery was indicated or it was abruptly performed as the results of lack of clinical improvement.

\section{Statistical analysis}

Student $t$ test was used to compare continuous variables, and Pearson chi-square test or Fisher exact test was used to compare categorical variable. Values of $p<0.05$ were considered statistically significant. SPSS statistics for Windows, PASW version 17.0 (SPSS Inc., Chicago, IL, USA), was used for all statistical analyses.

\section{RESULTS}

\section{Diagnostic yield of CT-guided bone biopsy}

During the study period between 1996 and 2008, a total of 1,027 cases were screened to have had undergone CT-guided bone biopsy. Of them, 927 were excluded; 898 malignancy and non-septic discitis; 29 incomplete medical records. Only one hundred patients have been diagnosed and treated as infectious spondylitis among recipients of CT-guided bone biopsy over the 13 year- study period.

Of 100 patients, 67 were identified to have pyogenic spondylitis. Definite diagnosis for pyogenic spondylitis were made in 36 patients because bacterial and fungal growing was confirmed in those ( 32 and 4 ), whereas possible diagnosis were made in 31 patients who had been treated with antibacterial agents based on clinical and laboratory supports without microbiologic evidence. Thirty-three patients were diagnosed to have tuberculous spondylitis. Definite growth of Mycobacterium tuberculosis was confirmed in 13 patients. Histopathological analyses of vertebral marrow showed granuloma with caseating necrosis in nine patients, suggesting probable tuberculosis. Eleven patients were treated with antituberculous agents based on clinical diagnosis and referred to possible group.

Microbiologic and pathologic yield of CT-guided bone biopsy for diagnosing definite and probable infectious spondylitis was shown in Table 1 . In pyogenic spondylitis group, of 36 confirmed cases, 22 micro-organisms were recovered from bone specimens obtained by biopsies and remaining 14 organisms were from blood and other tissues, which were not obtained from CT-guided biopsy. This resulted in 33\% of diagnostic yield of CT-guided bone biopsy for pyogenic spondylitis. Definite growth of $M$. tuberculosis in 13 patients was identified respectively from 11 bone specimens and two sputum cultures. Nine pathologic results from bone marrows had assisted to make a diagnosis for probable tuberculous spondylitis. Among a total of 33 tuberculosis cases, 20 were identified by test results from bone specimens, which had yielded $61 \%$ of diagnosis of tuberculosis.

Table 1. Microbiologic and pathologic yield of computed tomography-guided bone biopsy

\begin{tabular}{lccc}
\hline & Total no. $(\%)$ & \multicolumn{2}{c}{ No. of cases (\%) } \\
\cline { 3 - 4 } Infectious spondylitis & $(\mathrm{n}=100)$ & $\begin{array}{c}\text { Pyogenic } \\
\text { spondylitis }(\mathrm{n}=67)\end{array}$ & $\begin{array}{c}\text { Tuberculous } \\
\text { spondylitis }(\mathrm{n}=33)\end{array}$ \\
\hline Definite and probable cases & $58(58)$ & $36(54)$ & $22(67)$ \\
Proven by bone tissue obtained from CT-guided bone biopsy & $42(42)$ & $22(33)$ & $20(61)$ \\
Proven by other tissues not obtained from CT-guided biopsy & $16(16)$ & $14(21)$ & $2(6)$ \\
\hline
\end{tabular}

CT, computed tomography. 


\section{Clinical characteristics of tuberculous and pyogenic groups}

Clinical characteristics of patients with tuberculous and pyogenic spondylitis are compared in Table 2. The me- dian age was 56 years and males were predominant in the pyogenic group $(68.7 \%)$ compared with the tuberculous group $(45.5 \%, p=0.044)$. Patients presented with spinal disease (26\%), diabetes (13\%), and hypertension (13\%).

Table 2. Clinical characteristics in groups of pyogenic and tuberculous spondylitis

\begin{tabular}{|c|c|c|c|c|}
\hline \multirow[b]{2}{*}{ Variable } & \multicolumn{3}{|c|}{ No. of cases (\%) } & \multirow[b]{2}{*}{$p$ value } \\
\hline & $\begin{array}{c}\text { Total } \\
(\mathrm{n}=100)\end{array}$ & $\begin{array}{l}\text { Pyogenic spondylitis } \\
\qquad(\mathrm{n}=67)\end{array}$ & $\begin{array}{l}\text { Tuberculous spondylitis } \\
\qquad(\mathrm{n}=33)\end{array}$ & \\
\hline Age, yr & $56(43-64)$ & $57(42-66)$ & $54(44-4)$ & 0.892 \\
\hline Male sex & $61(61)$ & $46(68.7)$ & $15(45.5)$ & 0.044 \\
\hline Fever & $46(46)$ & $35(52.2)$ & $11(33 \cdot 3)$ & 0.038 \\
\hline \multicolumn{5}{|l|}{ Underlying disease } \\
\hline Diabetes & $13(13)$ & $7(10.4)$ & $6(18.2)$ & 0.360 \\
\hline Hypertension & $13(13)$ & $6(9.0)$ & $7(21.2)$ & 0.127 \\
\hline Renal insufficiency & $6(6)$ & $2(3.0)$ & $4(12.1)$ & 0.177 \\
\hline Chronic liver disease & $4(4)$ & $3(4 \cdot 5)$ & $1(3.0)$ & 1.000 \\
\hline Spinal disease & $26(26)$ & $23(34 \cdot 3)$ & $3(9.1)$ & 0.004 \\
\hline Others & $25(25)$ & $15(22.4)$ & $10(30.3)$ & 0.491 \\
\hline Involved spines & & & & 0.002 \\
\hline Cervical thoracolumbar & $29(29)$ & $12(17.9)$ & $17(51.5)$ & \\
\hline Cervical & $1(1)$ & o & $1(3.0)$ & \\
\hline Thoracic & $19(19)$ & $8(11.9)$ & $11(33 \cdot 3)$ & \\
\hline Thoracolumbar & $9(9)$ & $4(6.0)$ & $5(15.2)$ & \\
\hline Lumbar-sacral & $69(69)$ & $53(79.1)$ & $16(48.5)$ & \\
\hline Lumbar & $56(56)$ & $41(61.2)$ & $15(45.5)$ & \\
\hline Lumbosacral & $13(13)$ & $12(17.9)$ & $1(3.0)$ & \\
\hline Extensive & $2(2)$ & $2(3.0)$ & o & \\
\hline Presence of abscess ${ }^{\mathrm{a}}$ & $49(49)$ & $30(44.8)$ & $19(57.6)$ & 0.229 \\
\hline \multicolumn{5}{|l|}{ Index of inflammation } \\
\hline WBC, $\times 1,000$ cells $/ \mu \mathrm{L}$ & $7,760(6,300-10,020)$ & $8,050(6,712-10,140)$ & $6,800(5,670-9,075)$ & 0.016 \\
\hline $\mathrm{ESR}, \mathrm{mm} / \mathrm{hr}$ & $58.00(28.00-79.00)$ & $64.50(42.25-88.50)$ & $52.00(22.00-70.50)$ & 0.038 \\
\hline $\mathrm{CRP}, \mathrm{mg} / \mathrm{dL}$ & $3.43(0.97-7.61)$ & $4.07(1.64-9.05)$ & $2.55(0.71-5.01)$ & 0.179 \\
\hline Surgical intervention & $46(46)$ & $30(44.8)$ & $16(48.5)$ & \\
\hline Early (within 1 month) & $30(30)$ & $23(76.7)$ & $7(43.8)$ & \\
\hline Late (after 1 month) & $16(16)$ & $7(23 \cdot 3)$ & $9(56.3)$ & 0.026 \\
\hline 30-Day mortality & $3(3)$ & $2(3.0)$ & $1(3.0)$ & \\
\hline Repetitive surgery & $1(1)$ & o & $1(3.0)$ & \\
\hline Unknown, follow-up loss & $12(12)$ & $7(10.4)$ & $5(15.2)$ & \\
\hline Hospital stay & $32(19-50)$ & $38(24-52)$ & $21(9-35)$ & 0.003 \\
\hline
\end{tabular}

Values are presented as median (interquartile range) or number (\%). Characteristics of groups between pyogenic and tuberculous spondylitis were compared in the analysis including definite, probable, and possible cases.

WBC, white blood cell count; ESR, erythrocyte sedimentation rate; CRP, C-reactive protein.

${ }^{a}$ Abscess at psoas muscles, epidural space, and paravertebral area. 
The most commonly involved vertebrae were lumbar (56\%), followed by thoracic (19\%) and thoracolumbar (9\%). Cervical thoracolumbar vertebrae were more commonly involved in the tuberculous group $(51.5 \%)$ than in the pyogenic group (17.9\%), with statistical significance $(p=0.002)$. More than three ranges of spines were extensively involved in only in one case, which was caused by Pseudomonas aeruginosa. An abscess in the psoas muscles or in the epidural or paravertebral space was observed in $49 \%$ of patients. Patients with pyogenic spondylitis more frequently presented with fever accompanied by an increase in inflammatory markers than did those with tuberculosis. A total of 11 cases were identified to have sure gical site infection which occurred within 3 months after spine surgery in pyogenic spondylitis group.

Surgical intervention was performed in $46 \%$ of spondylitis cases. Sixteen patients (16\%) underwent surgery 1 month after diagnosis despite medical treatment: these included nine cases of tuberculous spondylitis and seven cases of pyogenic one ( $56.3 \%$ vs. $23.3 \%, p=0.026$ ). There were no differences between the two groups with respect to rates of 30-day mortality and repetitive surgery. Patients with pyogenic spondylitis had stayed longer in hospital than had those with tuberculous spondylitis ( 38 days vs. 21 days, $p=0.003$ ).

\section{Microbiological data}

Thirty-eight isolates were recovered in 36 patients of definite pyogenic groups. Mixed organisms were found in two patients with methicillin-susceptible Staphylococcus aureus and Streptococcus viridans and methicillin-resistant S. aureus and Enterococcus faecalis. S. aureus was the most commonly recovered isolate, accounting for $47 \%$ of cases with definite pyogenic spondylitis. Gram-negative organisms were cultivated in eight patients (21\%). Fungus was recovered in four patients (11\%), and all of these cases were related to surgical site infection. Detailed microbiological results are provided in Table 3.

\section{Comparison between culture-positive and negative groups with bacterial infection}

Characteristics of patients with positive culture results in definite bacterial infection group were compared with those who had negative culture results in possible group (Table 4). Four fungal cases were excluded in this analysis. The rates of prior antimicrobial treatment were
Table 3. Isolated organisms

\begin{tabular}{|c|c|}
\hline Isolated organism & $\begin{array}{l}\text { No. of isolates }(\%) \\
(n=38)\end{array}$ \\
\hline Gram-positive organisms & $26(68.4)$ \\
\hline Staphylococcus species & $21(55 \cdot 3)$ \\
\hline Staphylococcus aureus & $18(47 \cdot 4)$ \\
\hline Methicillin-susceptible ${ }^{a}$ & $17(44 \cdot 7)$ \\
\hline Methicillin-resistant ${ }^{\mathrm{b}}$ & $1(2.6)$ \\
\hline Coagulase-negative staphylococcus & $3(7 \cdot 9)$ \\
\hline Methicillin-susceptible & $2(5 \cdot 3)$ \\
\hline Methicillin-resistant & $1(2.6)$ \\
\hline Streptococcus species ${ }^{\mathrm{a}}$ & $2(5 \cdot 3)$ \\
\hline Enterococcus species ${ }^{\mathrm{b}}$ & $2(5 \cdot 3)$ \\
\hline Gram negative organisms & $8(21.1)$ \\
\hline Klebsiella pneumoniae & $2(5 \cdot 3)$ \\
\hline Pseudomonas aeruginosa & $2(5 \cdot 3)$ \\
\hline Escherichia coli & $1(2.6)$ \\
\hline Alcaligenes xylosoxidans & $1(2.6)$ \\
\hline Burkholderia cepacia & $1(2.6)$ \\
\hline Salmonella Paratyphi A & $1(2.6)$ \\
\hline Fungus & $4(10.5)$ \\
\hline Aspergillus fumigatus & $3(7 \cdot 9)$ \\
\hline Candida albicans & $1(2.6)$ \\
\hline
\end{tabular}

$\overline{{ }^{a} \text { Mixed organisms with methicillin-susceptible S. aureus and }}$ Streptococcus viridans in one patient.

${ }^{\mathrm{b}}$ Mixed organisms with methicillin-resistant $S$. aureus and Enterococcus faecalis in one patient.

not different between the two groups. An increase in inflammatory markers was observed in the culture-positive group, in particular the WBC and CRP levels. Clinical outcomes were not different between the two groups.

\section{Late surgical intervention}

A late surgical approach was attempted in 16 patients with nine cases of tuberculosis and seven cases of pyogenic spondylitis, including probable and possible diagnoses (Table 5). Five patients with spinal tuberculosis had accompanying pulmonary infection. When we analysed the reasons for late surgery, most cases were related to lack of clinical improvement related to aggravation of back pain, progression of abscess and neurologic deficit. In four tuberculous spondylitis cases, delayed surgery was planned intentionally at the time of 
Table 4. Clinical characteristics in patients with culture-positive and negative results in bacterial infection group

\begin{tabular}{|c|c|c|c|}
\hline \multirow{2}{*}{ Variable } & \multicolumn{2}{|c|}{ No. of patients } & \multirow{2}{*}{$p$ value } \\
\hline & Culture-positive $(\mathrm{n}=32)$ & Culture-negative $(\mathrm{n}=31)$ & \\
\hline Age, yr & $57(42-69)$ & $55(40-62)$ & 0.487 \\
\hline Male sex & $23(71.9)$ & $19(61.3)$ & 0.373 \\
\hline Underlying disease & $24(75.0)$ & $18(58.1)$ & 0.154 \\
\hline Previous antibiotic-usage & $21(65.6)$ & $14(45 \cdot 2)$ & 0.102 \\
\hline Fever & $12(37 \cdot 5)$ & $13(41.9)$ & 0.719 \\
\hline Index of inflammation & 32 & 30 & \\
\hline WBC, $\times 1,000$ cells $/ \mu \mathrm{L}$ & $8,290(6,640-14,930)$ & $7,990(6,700-9,360)$ & 0.011 \\
\hline $\mathrm{ESR}, \mathrm{mm} / \mathrm{hr}$ & $66.5(52.8-98.8)$ & $61.0(31.8-84.8)$ & 0.075 \\
\hline $\mathrm{CRP}, \mathrm{mg} / \mathrm{dL}$ & $6.95(3.37-13.63)$ & $2.30(0.68-4.24)$ & $<0.001$ \\
\hline Surgical intervention & $16(50.0)$ & $11(35 \cdot 5)$ & 0.244 \\
\hline Clinical improvement $^{\mathrm{a}}$ & $28(87 \cdot 5)$ & $27(87.1)$ & 0.263 \\
\hline Hospital stay & $42(28-55)$ & $31(35-50)$ & 0.064 \\
\hline
\end{tabular}

Values are presented as median (interquartile range) or number (\%). Characteristics between patients with definite and possible bacterial infections were compared. Four fungal cases were not introduced in this analysis.

WBC, white blood cell count; ESR, erythrocyte sedimentation rate; CRP, C-reactive protein.

${ }^{a}$ Assessment at at 4 weeks during the course of therapy.

diagnosis even though patients presented with epidural and paravertebral abscesses. In these cases, attending physicians have decided to observe the response of antituberculosis treatment and delay the surgery for at least 1 month, expecting the improvement of spondylitis by medical therapy. The size of the abscess in four patients, at the time of assessment of clinical response, was not improved despite antituberculous therapy, which had resulted in the late surgery.

\section{DISCUSSION}

This study evaluated the diagnostic yield of CT-guided bone biopsy for infectious spondylitis in a country with a high prevalence of tuberculosis. Microbiological and pathologic data obtained by CT-guided bone biopsy contributed to the prompt diagnosis of spinal infection, especially in cases with tuberculosis, which showed a $60 \%$ diagnostic yield. The value of percutaneous biopsy had been analysed in previous studies with yields ranging from $40 \%$ to $70 \%[7,10,11,14]$. The $60 \%$ yield of CT-guided bone biopsy in diagnosing tuberculous spondylitis achieved in this study is in accordance with results from previous studies. Even though prior stud- ies have already reported the high yield of percutaneous biopsy for the diagnosis of tuberculosis, these studies did not target subjects who underwent CT-guided bone biopsy. Most of the research issues associated with spinal tuberculosis have been confined to the diagnostic modality of MRI and clinical outcomes [2,6,15]. In such a situation lacking the evidence provided by specimens obtained under the guidance of CT, our study has significance in having evaluated a large number of patients and provided a comprehensive conclusion.

The utility of inflammatory markers for the differentiation between tuberculous and bacterial etiology was previously investigated in community-acquired pneumonia. A marked increase in inflammatory markers was strongly associated with a bacterial etiology and disease severity in pneumonia $[16,17]$. Comparative studies of pyogenic and tuberculous spinal infections have investigated the association between an increased ESR and pyogenic spondylitis, but the results were not sufficiently consistent to show a significant association $[11,18]$. The results of the present study showing a strong association between inflammatory markers and pyogenic spondylitis are expected to be valuable in discriminating the bacteria from tuberculosis.

The culture-negative rate was approximately 50\% for 
Table 5. Late surgical attempts in 16 patients

\begin{tabular}{|c|c|c|c|c|c|c|c|c|c|c|}
\hline No. & Age & Sex & $\begin{array}{c}\text { Clinical } \\
\text { diagnosis }\end{array}$ & Comorbidity & $\begin{array}{l}\text { Time of } \\
\text { surgery }\end{array}$ & Abscess & $\begin{array}{l}\text { Reasons for } \\
\text { late surgery }\end{array}$ & Level & $\begin{array}{c}\text { Treatment } \\
\text { regimen }\end{array}$ & $\begin{array}{l}\text { Duration, } \\
\text { mon }\end{array}$ \\
\hline 1 & 52 & $\mathrm{~F}$ & $\begin{array}{l}\text { Tuberculous, } \\
\text { possible }\end{array}$ & $\begin{array}{l}\text { Pulmonary } \\
\text { TB }\end{array}$ & 72 & Yes & $\begin{array}{l}\text { Delayed } \\
\text { surgery }\end{array}$ & T6-8 & HREZ & 18 \\
\hline 2 & 50 & $\mathrm{~F}$ & $\begin{array}{l}\text { Tuberculous, } \\
\text { probable }\end{array}$ & No & 71 & Yes & $\begin{array}{l}\text { Progression } \\
\text { of abscess }\end{array}$ & $\mathrm{L}_{3}-4$ & HREZ & 17 \\
\hline 3 & 73 & $\mathrm{M}$ & $\begin{array}{l}\text { Tuberculous, } \\
\text { possible }\end{array}$ & HTN & 54 & Yes & $\begin{array}{l}\text { Progression } \\
\text { of abscess }\end{array}$ & T10-11 & HREZ & 10 \\
\hline 4 & 21 & $\mathrm{M}$ & $\begin{array}{l}\text { Pyogenic, } \\
\text { definite }\end{array}$ & No & 126 & No & $\begin{array}{l}\text { Neurologic } \\
\text { deficit }\end{array}$ & $\mathrm{L}_{4-5}$ & $\begin{array}{l}\text { PIP/TAZ, CFTZ, } \\
\text { SMX/TMP }\end{array}$ & 6 \\
\hline 5 & 43 & $\mathrm{M}$ & $\begin{array}{l}\text { Tuberculous, } \\
\text { definite }\end{array}$ & $\begin{array}{l}\text { Pulmonary } \\
\text { TB }\end{array}$ & 38 & Yes & $\begin{array}{l}\text { Progression } \\
\text { of abscess }\end{array}$ & T10-12 & HREZ & 18 \\
\hline 6 & 61 & $\mathrm{~F}$ & $\begin{array}{l}\text { Tuberculous, } \\
\text { definite }\end{array}$ & $\begin{array}{l}\text { Pulmonary } \\
\text { TB }\end{array}$ & 56 & No & $\begin{array}{l}\text { Delayed } \\
\text { surgery }\end{array}$ & $\mathrm{L} 2-3$ & HREZ & 14 \\
\hline 7 & 54 & $\mathrm{M}$ & $\begin{array}{l}\text { Pyogenic, } \\
\text { possible }\end{array}$ & HIVD & 48 & Yes & $\begin{array}{l}\text { Aggravation } \\
\text { of back pain }\end{array}$ & $\mathrm{L}_{4-5}$ & CFZ, CIP, CLND & 2.5 \\
\hline 8 & 47 & $\mathrm{~F}$ & $\begin{array}{l}\text { Tuberculous, } \\
\text { probable }\end{array}$ & $\begin{array}{l}\text { Pulmonary } \\
\text { TB }\end{array}$ & 55 & Yes & $\begin{array}{l}\text { Delayed } \\
\text { surgery }\end{array}$ & $\mathrm{T} 12-\mathrm{L} 1$ & HREZ & 15 \\
\hline 9 & 54 & $\mathrm{M}$ & $\begin{array}{l}\text { Pyogenic, } \\
\text { definite }\end{array}$ & HIVD & 195 & Yes & $\begin{array}{l}\text { Relapsed } \\
\text { infection }\end{array}$ & $\mathrm{L}_{4-5}$ & Fluconazole & 2 \\
\hline 10 & 44 & M & $\begin{array}{l}\text { Tuberculous, } \\
\text { probable }\end{array}$ & HIVD & 306 & No & $\begin{array}{l}\text { Neurologic } \\
\text { deficit }\end{array}$ & $\mathrm{L} 2-3$ & HREZ & 12 \\
\hline 11 & 22 & $\mathrm{~F}$ & $\begin{array}{l}\text { Tuberculous, } \\
\text { probable }\end{array}$ & $\begin{array}{l}\text { Pulmonary } \\
\text { TB }\end{array}$ & 50 & Yes & $\begin{array}{l}\text { Progression } \\
\text { of abscess }\end{array}$ & $\mathrm{L} 1-2$ & HREZ & 14 \\
\hline 12 & 25 & M & $\begin{array}{l}\text { Pyogenic, } \\
\text { possible }\end{array}$ & HIVD & 67 & No & $\begin{array}{l}\text { Neurologic } \\
\text { deficit }\end{array}$ & $\mathrm{L}_{3}-4$ & $\mathrm{CFZ} \rightarrow \mathrm{CIP}, \mathrm{CLND}$ & 2 \\
\hline 13 & 60 & $\mathrm{~F}$ & $\begin{array}{l}\text { Pyogenic, } \\
\text { possible }\end{array}$ & Behcet & 81 & Yes & $\begin{array}{l}\text { Progression } \\
\text { of abscess }\end{array}$ & $\mathrm{L}_{5}$ & $\mathrm{CFZ} \rightarrow \mathrm{CIP}, \mathrm{RFP}$ & 12 \\
\hline 14 & 78 & $\mathrm{~F}$ & $\begin{array}{l}\text { Pyogenic, } \\
\text { possible }\end{array}$ & HTN & 59 & No & $\begin{array}{l}\text { New abscess } \\
\text { formation }\end{array}$ & $\mathrm{L}_{3}-\mathrm{S}$ & $\begin{array}{l}\text { CTRX, } \\
\text { VANC } \rightarrow \text { LFLX, } \\
\text { RFP }\end{array}$ & 4 \\
\hline 15 & 69 & $\mathrm{M}$ & $\begin{array}{l}\text { Pyogenic, } \\
\text { definite }\end{array}$ & LC, CRF & 61 & Yes & $\begin{array}{l}\text { Progression } \\
\text { of abscess }\end{array}$ & $\mathrm{T} 11-12$ & MERO & 2.5 \\
\hline 16 & 57 & $\mathrm{~F}$ & $\begin{array}{l}\text { Tuberculous, } \\
\text { definite }\end{array}$ & HIVD & 102 & Yes & $\begin{array}{l}\text { Delayed } \\
\text { surgery }\end{array}$ & $\mathrm{C} 6-\mathrm{T}_{3}$ & HREZ & 15 \\
\hline
\end{tabular}

TB, tuberculosis; HREZ, isoniazid + rifampicin + ethambutol + pyrazinamide; HTN, hypertension; PIP/TAZ, piperacillin/ tazobactam; CFTZ, ceftazidime; SMX/TMP, sufamethoxazole/trimethoprim; HIVD, herniated intervertebral disc; CFZ, cefazolin; CIP, ciprofloxacin; CLND, clindamycin; RFP, rifampicin; CTRX, ceftriaxone; VANC, vancomycin; LFLX, levofloxacin; LC, liver cirrhosis; CRF, chronic renal failure; MERO, meropenem.

all of bacterial spondylitis cases in this study. To identify factors associated with culture-negative results, we compared the culture-positive and -negative groups. Patients in the culture-negative group presented with a lower CRP and a lower ESR compared with those of the culture-positive group, and previous antimicrobial ther- apy did not affect the negative results. In the previous study of evaluating the impact of prior antibiotic exposure on the results of culture in patients with infectious spondylitis, the presence of paravertebral abscess, elevated WBC, CRP levels were related to positive outcome, whereas longer duration of previous antibiotic expo- 
sure, 4 or more days was related to negative outcome [19]. According to the results of this study, although we have investigated duration of previous antibiotic exposure, we couldn't find the exact data for duration of antibiotic exposure. These findings might reflect the fact that this study was conducted in a tertiary-care hospital to which most of the patients were referred during antimicrobial therapy, and data concerning prescriptions given outside of the hospital may be incorrect. Alternatively, the negative culture result might be a reflection of a less extensive inflammatory process triggered by a low grade infection [2o]. It is also possible that samples were collected at the site devoid of organisms, resulting in a false-negative result [21]. Given the concerns surrounding a possible false-negative result, a repeat biopsy might be considered when the first biopsy is negative.

In past decades, radical resection of the tuberculosis-infected focus and bone grafting was suggested as a general approach for the treatment of spinal tuberculosis in patients with severe neurological deficits. With the advent of imaging modalities and effective treatment regimens, a non-operative approach was subsequently introduced for those with spinal tuberculosis and neurologic deficits [22]. However, delayed surgery for late onset complications involves the risk of neural deterioration and vertebral destruction leading to severe kyphosis [23]. In our study, 16 patients underwent delayed operation after the lack of improvement by medical approaches; of these, late surgery had been originally planned for four cases. Upon further investigation into these cases of late surgery for spinal tuberculosis, disease progression including kyphosis and spinal instability was observed in a total of nine cases despite administration of more effective antituberculous agents. These deteriorating outcomes in cases of delayed surgery raise concerns regarding trials that delay the initial surgical approach indicated at the time of diagnosis. According to a study that evaluated prognostic factors influencing the outcomes of patients with spinal tuberculosis, radical surgery was significantly related to a favourable outcome and a large number of involved vertebrae was related to the progression of kyphosis [2,24]. Considering these outcomes of surgical treatment in spinal tuberculosis, it is important to cautiously select cases that are predicted to deteriorate during medical treatment for early-radical operation, especially those involving more than two vertebrae and with expected kyphosis [2,24]. If it is not possible to undergo an early-radical approach in adversely predicted cases, it is mandatory to perform short-term follow-up for early recognition of impending neurologic deficits.

This study has several limitations. First, it was a retrospective design with a small sample size that was not sufficient to show statistical power. Because clinical data regarding initial presentations and outcomes were collected retrospectively, initial clinical presentation and additional data that could be helpful to assess possible portals of entry in patients with spondylitis were not described precisely. A second limitation concerns the problems associated with a large single center study in a tertiary to which most of the patients were referred from other institutions. This might result in an inaccurate assessment of previous antimicrobial usage outside of this hospital and may lead to a large number of negative-cultural reports; thus, underestimating the exact diagnostic yield of bone biopsy in pyogenic spondylitis. Finally, there is the possibility of inaccurate diagnoses in cases of possible spondylitis. Among antituberculous agents, rifampin, and fluoroquinolone are known to be active against staphylococcal infection. Many cases that were treated as possible tuberculosis might have been culture-negative pyogenic spondylitis. To adjust for possible misdiagnoses between tuberculosis and bacterial etiologies, we classified cases into definite, probable, and possible groups. The clinical characteristics of tuberculous and pyogenic spondylitis infections showed consistent results even after adjusting for possible cases.

In conclusion, microbiological and pathologic data obtained by CT-guided bone biopsy contributed to a prompt diagnosis of spinal infection, especially the $60 \%$ diagnostic yield caused by tuberculosis. Pyogenic spondylitis was associated with fever more frequently than was tuberculous spondylitis. Despite early administration of antituberculous agents, patients with tuberculosis tended to show progression of inflammatory and destructive processes, leading to late surgical intervention. With the current increasing prevalence of both tuberculous and pyogenic spinal infections, CT-guided bone biopsy is expected to serve as an effective modality for the prompt diagnosis and proper management of infectious spondylitis. 


\section{KEY MESSAGE}

1. Microbiological and pathologic data obtained by computed tomography (CT)-guided bone biopsy contributed to an effective diagnosis of spinal infection, especially the $60 \%$ diagnostic yield caused by tuberculosis.

2. Despite early administration of anti-tuberculous agents, patients with tuberculosis tended to show progression of inflammatory and destructive processes, leading to late surgical intervention.

3. CT-guided bone biopsy is expected to serve as an effective modality for the prompt diagnosis and proper management of infectious spondylitis.

\section{Conflict of interest}

No potential conflict of interest relevant to this article was reported.

\section{REFERENCES}

1. Cottle L, Riordan T. Infectious spondylodiscitis. J Infect 2008;56:401-412.

2. Park DW, Sohn JW, Kim EH, et al. Outcome and management of spinal tuberculosis according to the severity of disease: a retrospective study of 137 adult patients at Korean teaching hospitals. Spine (Phila Pa 1976) 2007;32:E130-E135.

3. Kenyon PC, Chapman AL. Tuberculous vertebral osteomyelitis: findings of a 10-year review of experience in a UK centre. J Infect 2009;59:372-373.

4. Wang D. Diagnosis of tuberculous vertebral osteomyelitis (TVO) in a developed country and literature review. Spinal Cord 2005;43:531-542.

5. Petitjean G, Fluckiger U, Scharen S, Laifer G. Vertebral osteomyelitis caused by non-tuberculous mycobacteria. Clin Microbiol Infect 2004;10:951-953.

6. Tali ET. Spinal infections. Eur J Radiol 2004;50:120-133.

7. Enoch DA, Cargill JS, Laing R, Herbert S, Corrah TW, Brown NM. Value of CT-guided biopsy in the diagnosis of septic discitis. J Clin Pathol 2008;61:750-753.

8. Nolla JM, Ariza J, Gomez-Vaquero C, et al. Spontaneous pyogenic vertebral osteomyelitis in nondrug users. Se- min Arthritis Rheum 2002;31:271-278.

9. Hau A, Kim I, Kattapuram S, et al. Accuracy of CT-guided biopsies in 359 patients with musculoskeletal lesions. Skeletal Radiol 2002;31:349-353.

10. Luzzati R, Giacomazzi D, Danzi MC, Tacconi L, Concia E, Vento S. Diagnosis, management and outcome of clinically: suspected spinal infection. J Infect 2009;58:259-265.

11. Turunc T, Demiroglu YZ, Uncu H, Colakoglu S, Arslan H. A comparative analysis of tuberculous, brucellar and pyogenic spontaneous spondylodiscitis patients. J Infect 2007:55:158-163.

12. Kim SH, Cho OH, Park SJ, et al. Rapid diagnosis of tuberculous meningitis by $\mathrm{T}$ cell-based assays on peripheral blood and cerebrospinal fluid mononuclear cells. Clin Infect Dis 2010;50:1349-1358.

13. Zimmerli W. Clinical practice: vertebral osteomyelitis. N Engl J Med 2010;362:1022-1029.

14. Colmenero JD, Jimenez-Mejias ME, Reguera JM, et al. Tuberculous vertebral osteomyelitis in the new millennium: still a diagnostic and therapeutic challenge. Eur J Clin Microbiol Infect Dis 2004;23:477-483.

15. Pertuiset E, Beaudreuil J, Liote F, et al. Spinal tuberculosis in adults: a study of 103 cases in a developed country, 1980-1994. Medicine (Baltimore) 1999;78:309-320.

16. Kang YA, Kwon SY, Yoon HI, Lee JH, Lee CT. Role of C-reactive protein and procalcitonin in differentiation of tuberculosis from bacterial community acquired pneumonia. Korean J Intern Med 2009;24:337-342.

17. Almirall J, Bolibar I, Toran P, et al. Contribution of C-reactive protein to the diagnosis and assessment of severity of community-acquired pneumonia. Chest 2004;125:13351342.

18. Colmenero JD, Jimenez-Mejias ME, Sanchez-Lora FJ, et al. Pyogenic, tuberculous, and brucellar vertebral osteomyelitis: a descriptive and comparative study of 219 cases. Ann Rheum Dis 1997;56:709-715.

19. Kim CJ, Song KH, Park WB, et al. Microbiologically and clinically diagnosed vertebral osteomyelitis: impact of prior antibiotic exposure. Antimicrob Agents Chemother 2012;56:2122-2124.

20. Bhagat S, Mathieson C, Jandhyala R, Johnston R. Spondylodiscitis (disc space infection) associated with negative microbiological tests: comparison of outcome of suspected disc space infections to documented non-tuberculous pyogenic discitis. Br J Neurosurg 2007;21:473-477.

21. Gillard J, Boutoille D, Varin S, Asseray N, Berthelot JM, 
Maugars Y. Suspected disk space infection with negative microbiological tests: report of eight cases and comparison with documented pyogenic discitis. Joint Bone Spine 2005;72:156-162.

22. Jain AK, Dhammi IK. Tuberculosis of the spine: a review. Clin Orthop Relat Res 2007;460:39-49.

23. Rajasekaran S. The natural history of post-tubercular ky- phosis in children: radiological signs which predict late increase in deformity. J Bone Joint Surg Br 2001;83:954962.

24. Rajasekaran S, Shanmugasundaram TK. Prediction of the angle of gibbus deformity in tuberculosis of the spine. J Bone Joint Surg Am 1987;69:503-509. 